\title{
Morfologia das brânquias de Steindachnerina brevipinna (Eigenmann \& Eigenmann, 1889) (Characiformes, Curimatidae)
}

\author{
Fernanda Blauth de Lima ${ }^{1 *}$ \\ Maria del Carmen Braccini ${ }^{1}$ \\ Alcira Ofélia Díaz ${ }^{2}$ \\ Clóvis Pinheiro Junior ${ }^{1}$ \\ Antônio Carlos Galarça Guimarães ${ }^{1}$ \\ ${ }^{1}$ Laboratório de Histologia e Embriologia \\ Pontifícia Universidade Católica do Rio Grande do Sul, Campus Uruguaiana \\ BR 472, Km 7, Caixa Postal 249, CEP 97500-970, Uruguaiana - RS, Brasil \\ ${ }^{2}$ Departamento de Biologia, Faculdade de Ciências Exactas y Naturales, UNMDP \\ Mar del Plata, Argentina \\ *Autor para Correspondência \\ Rua José Tovazzi, 1524, Apto 04, CEP 95072-300, Caxias do Sul - RS, Brasil \\ nandalima85@gmail.com
}

Submetido em 17/04/2008

Aceito para publicação em 01/09/2008

\section{Resumo}

O Birú, Steindachnerina brevipinna, é um peixe de hábito detritívoro. O presente estudo descreve a morfologia respiratória, contribuindo na determinação do hábito alimentar da espécie. O material foi processado de acordo com a metodologia de inclusão em parafina, corados com Hematoxilina \& Eosina, Tricrômico de Goldner e P.A.S. As brânquias apresentam arcos com rastros pequenos e numerosos, destacando-se os filamentos curtos e próximos entre si, quando comparados a outras espécies. Evidenciam-se corpúsculos gustativos, células mucosas, pavimentosas, clorídricas, entre outras. Nas lamelas, o epitélio é estratificado, com células pilares e mucosas. As características estruturais observadas nas brânquias de $S$. brevipinna refletem o estreito comprometimento com o hábito alimentar somado à intensa agilidade desta espécie.

Unitermos: Brânquias, morfologia, histologia, peixe dulciaqüícola, Steindachnerina brevipinna

\section{Abstract}

Morphology of the gills of Steindachnerina brevipinna (Eigenmann \& Eigenmann, 1889) (Characiformes, Curimatidae). The Birú, Steindachnerina brevipinna, is a fish of detritivorous habit. This study describes the respiratory morphology, which contributes to the determination of the species' feeding habits. The material was processed according to the methodology of paraffin inclusion, pigmented with Hematoxylin \& Eosin, Tricomic of Goldner, and P.A.S. The gills have arches with small and numerous filaments, which are short and close to one other, when compared to other species. Gustative corpuscles, mucous cells, pavement, cells and chloride cells were in evidence, among others. In the lamellae, the epithelium is stratified, with pillars and mucous cells. The structural characteristics observed in the gills of $S$. brevipinna reflect the narrow commitment with the feeding habit in addition to the intense agility of this species.

Key words: gills, morphology, histology, freshwater fish, Steindachnerina brevipinna 


\section{Introdução}

As brânquias dos peixes exercem papéis vitais, pois, além de serem o principal sítio de trocas gasosas, também estão envolvidas nos processos de osmorregulação, equilíbrio ácido-básico, excreção de compostos nitrogenados e gustação (Machado e Fanta, 2003).

Steindachnerina brevipinna (Eigenmann \& Eigenmann, 1889) pertence à família Curimatidae, que compreende diversas espécies popularmente conhecidas como birú, extremamente abundantes e de grande importância ecológica nas comunidades de peixes neotropicais, por serem animais de hábito detritívoro (Giora e Fialho, 2003).

Esta família apresenta distribuição geográfica restrita à América do Sul, com espécies forrageiras que se destacam na cadeia alimentar do ecossistema. Através de seu hábito alimentar, atua na matéria orgânica contida no lodo durante a fase de pré-mineralização, fornecendo às bactérias substrato facilmente decomponível, resultando no aumento da produtividade do ecossistema (Barbieri e Hartz, 1995).

Um ponto a se destacar é que a dimensão, a localização das brânquias e a organização dos filamentos e das lamelas permitem retirar conclusões sobre o hábito alimentar e hábitat de qualquer espécie de peixes (Mazon et al., 1998).
O presente estudo tem como objetivo, analisar a morfologia das brânquias de $S$. brevipinna e estabelecer a relação deste órgão com o hábito alimentar desta espécie, descrevendo aspectos histológicos branquiais, como a estrutura de filamentos, lamelas e rastros.

\section{Materiais e Métodos}

Os exemplares de S. brevipinna (Figura 1) foram coletados na Bacia Hidrográfica do Rio Uruguai Médio, (29³0'20,4'S; 56 50'41,9'W), no período de maio de 2005 a janeiro de 2006.

Trabalhou-se com quarenta exemplares adultos, de ambos os sexos, pesados e medidos no local de coleta, onde as brânquias foram retiradas e fixadas em formol 4\% tamponado conforme Díaz et al. (2001).

No laboratório de Histologia e Embriologia da PUCRS - Uruguaiana foi realizada a dissecação das brânquias. Empregou-se ao segundo arco branquial, técnicas histológicas usuais, com inclusão em parafina e obtenção de cortes de $5 \mu \mathrm{m}$ de espessura, corados com Hematoxilina - Eosina (HE) e Tricrômico de Goldner (TG) conforme Tolosa et al. (2003) e P.A.S. de acordo com McManus (1948). As lâminas foram analisadas em fotomicroscópio Olympus, trinocular, modelo CX 41 e as imagens foram capturadas através de uma câmera fotográfica Olympus, CAMEDIA C - 5060, de 5.1 megapixel, acoplado a um computador, através do programa Image-Pro Explress.

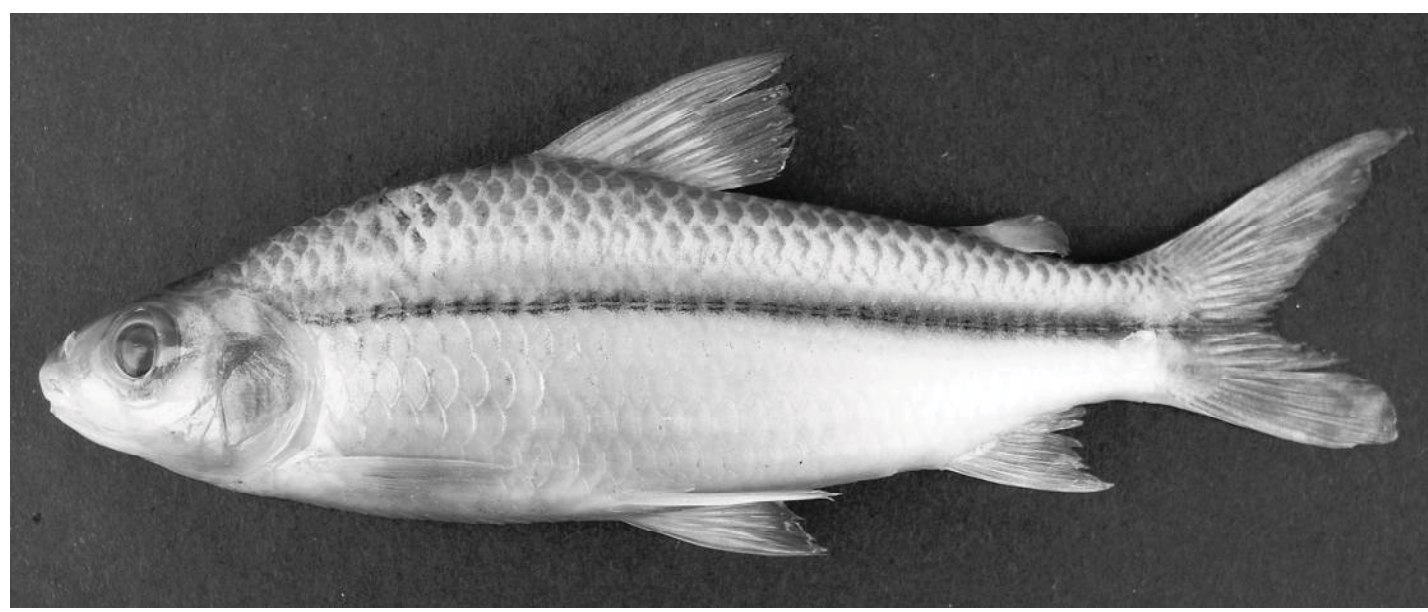

FIGURA 1: Exemplar de S. brevipinna da Bacia Hidrográfica do Rio Uruguai Médio (Lt 110mm). 


\section{Resultados e Discussão}

As características observadas nesta espécie vêm de encontro com Hughes e Byczkowska-Smyk (1974), afirmando, uma organização geral básica das brânquias de peixes, formadas por quatro pares de arcos branquiais, protegidos pelos opérculos (Figura 2) de onde partem filamentos constituídos por lamelas paralelas entre si e na região oposta observa-se diversos rastros. Porém, as diferenças encontradas em S. brevipinna estão relacionadas a hábitos particulares, como a grande quantidade de rastros de tamanhos reduzidos, presença de corpúsculos gustativos e células mucosas, conforme os autores, espécies que mantêm suas atividades ecológicas habituais, no ecossistema, durante longos períodos, sendo mais ágeis, têm a barreira água-sangue mais espessa do que peixes de menor atividade, o que é confirmada pelo intenso número de lamelas encontradas em S. brevipinna.

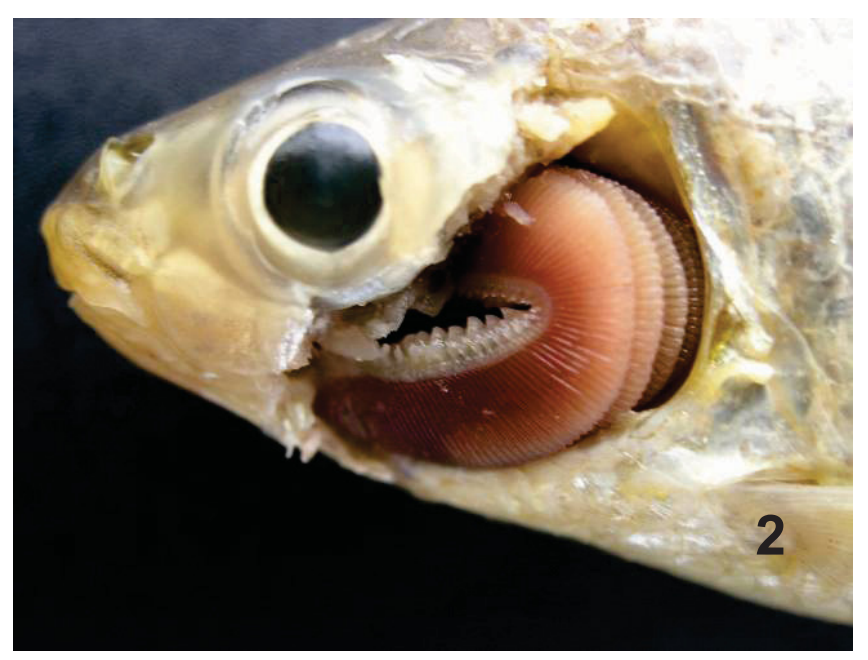

FIGURA 2: Vista geral das brânquias de S. Brevipinna.

Este arco branquial sustenta a parte funcional do órgão, apresentando uma curvatura muito acentuada, para Eiras-Stofella e Charvet-Almeida (1998) e EirasStofella (2000) esta curvatura juntamente com a grande quantidade de filamentos, somada ao tamanho reduzido dos rastros, também apresentada por S. brevipinna, pode estar vinculada ao hábito alimentar da espécie. Deste arco branquial partem duas colunas de filamentos, constituídos por lamelas paralelas entre si e na superfície oposta, os rastros (Figura 3).
Através das análises histológicas, observou-se que, o arco é formado por osso misto (Figura 4A), cartilagem hialina, musculatura estriada e variedades de tecido conjuntivo de sustentação, os quais penetram nos filamentos branquiais, levando consigo os ramos de artérias branquiais, facilmente visíveis (Figura 4B). Como afirma Sabóia-Moraes (1991), as arteríolas do filamento capilarizam-se e emitem seus ramos para as lamelas branquiais, as quais possuem fluxo contracorrente, mecanismo que auxilia nas trocas gasosas.

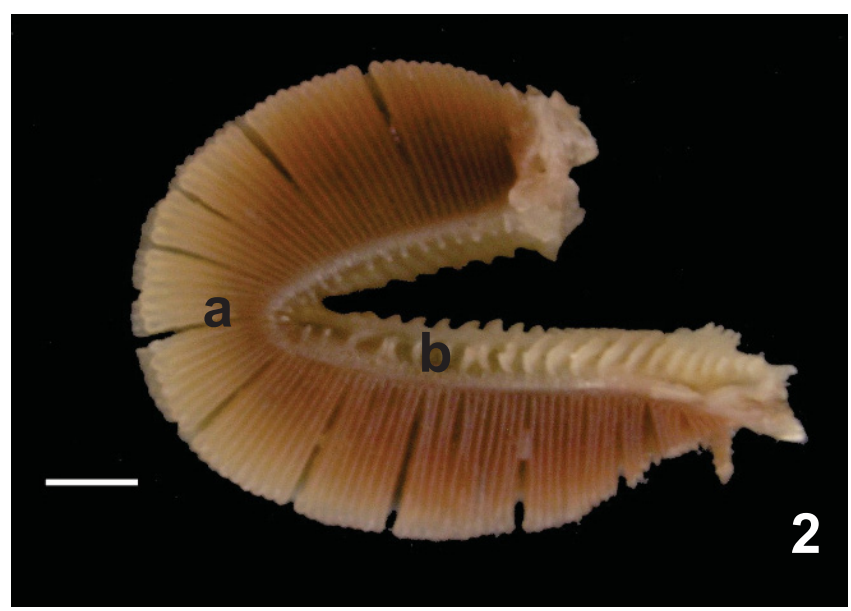

FIGURA 3: Morfologia do arco branquial de S. brevipinna. Filamento (a); rastro (b). Escala $1 \mathrm{~mm}$.

Os rastros branquiais estão localizados na curvatura interna do arco, sendo estruturas espinhosas, relacionadas à cavidade bucofaríngea, de tamanhos semelhantes entre si e de pequeno porte quando comparados às espécies de hábitos alimentares diferentes, como Plagioscion squamosissimus, estudado por Mazon et al. (1998), peixe carnívoro, enquanto $S$. brevipina é detritívora.

Estes rastros são formados por um eixo cartilaginoso, revestido por um epitélio estratificado com presença de corpúsculos gustativos, células mucosas e claviformes (Figura 5), semelhante à Mugil cephalus e Fundulus heteroclitus estudados por Hossler e Merchant (1983).

A presença dos corpúsculos gustativos evidencia a participação das brânquias de $S$. brevipinna no processo digestório, pois Eiras-Stofella e Charvet-Almeida (1998) afirmam que os corpúsculos apresentam receptores químicos, relacionados à detecção dos alimentos pela espécie. 

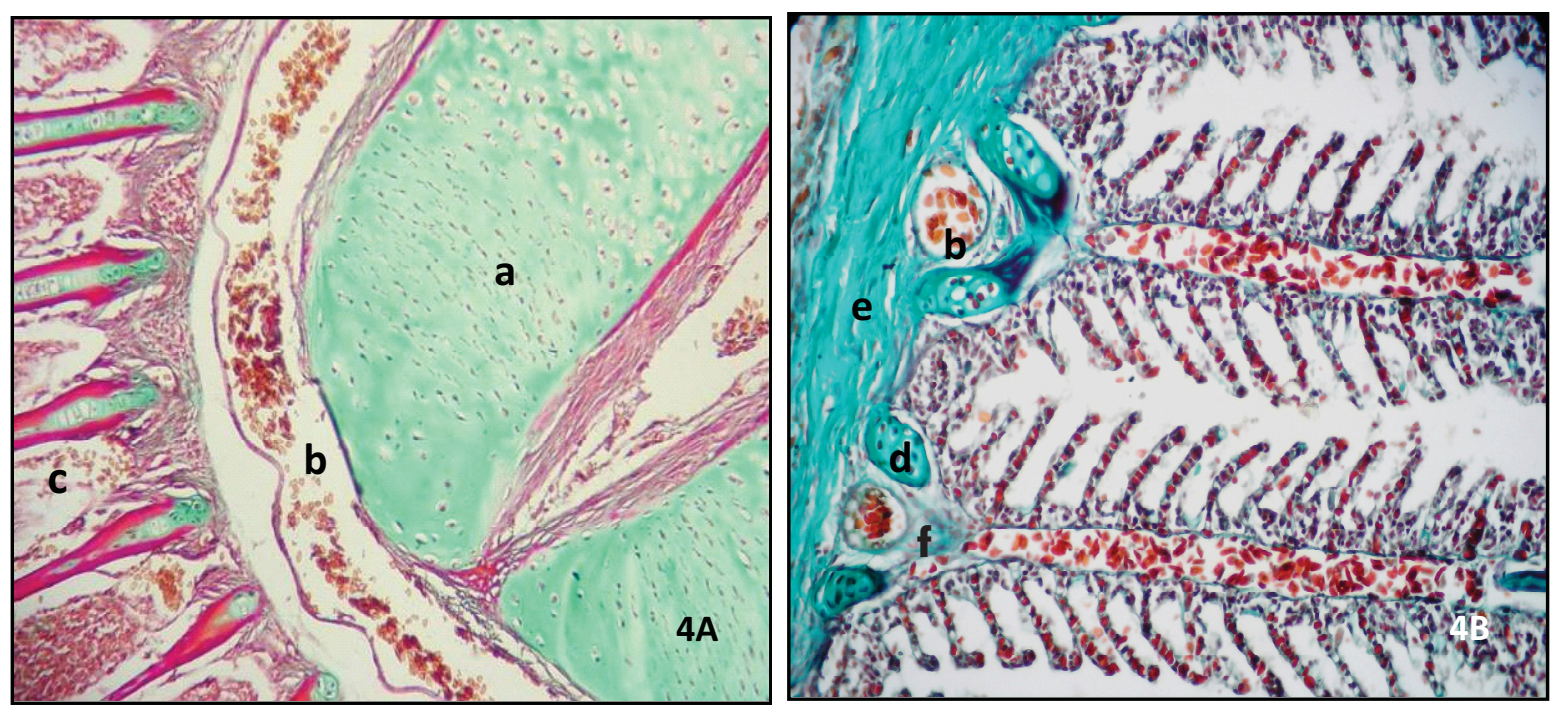

FIGURA 4: Componentes histológicos do arco branquial de S. brevipinna. 4A. Osso misto (a); irrigação principal (b); filamentos (c). Tricrômico de Goldner 100X. 4B. Artérias branquiais (b); Cartilagem hialina (d); musculatura estriada (e); tecido conjuntivo (f). TG. 400X.

As células claviformes estão localizadas predominantemente entre as células basais do epitélio estratificado do rastro, esse contato direto com o meio, indica o papel de proteção e defesa do organismo por estas estruturas, como também afirma Gremsky (1975).

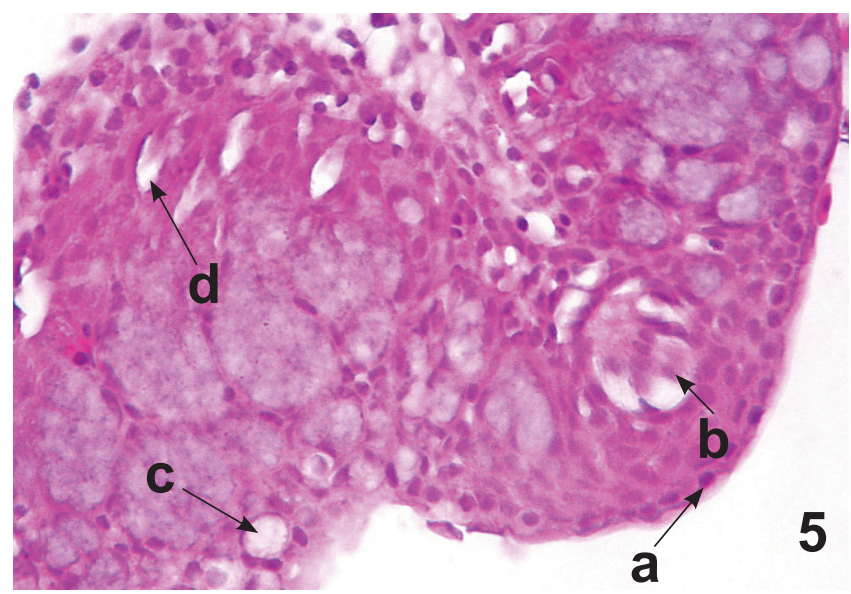

FIGURE 5: Rastros branquiais de S. brevipinna. Epitélio (a); corpúsculo gustativo (b); células mucosas (c) e claviformes (d). HE. 100X.

Os filamentos possuem um eixo de cartilagem hialina, revestidos por epitélio branquial multilamelar, com células mucosas e clorídricas (Figura 6).

As células clorídricas na espécie em estudo encontram-se isoladas, geralmente nos filamentos próximas às lamelas. King e Hossler (1991) ressaltam que podem apresentar-se desta forma ou em grupo, porém em geral sem criptas na membrana apical como nas espécies de água salgada. Para Eiras-Stofella et al. (2001) estudando três espécies do gênero Mugil não as encontrou apenas em $M$. curema. A presença dessas células está relacionada com a capacidade de osmorregulação (Hossler, 1980; Pisam et al., 2000) como afirmado por Eiras-Stofella e Charvet-Almeida (1998) ao observar um aumento significativo destas células em condições adversas, em Prochilodus scrofa.

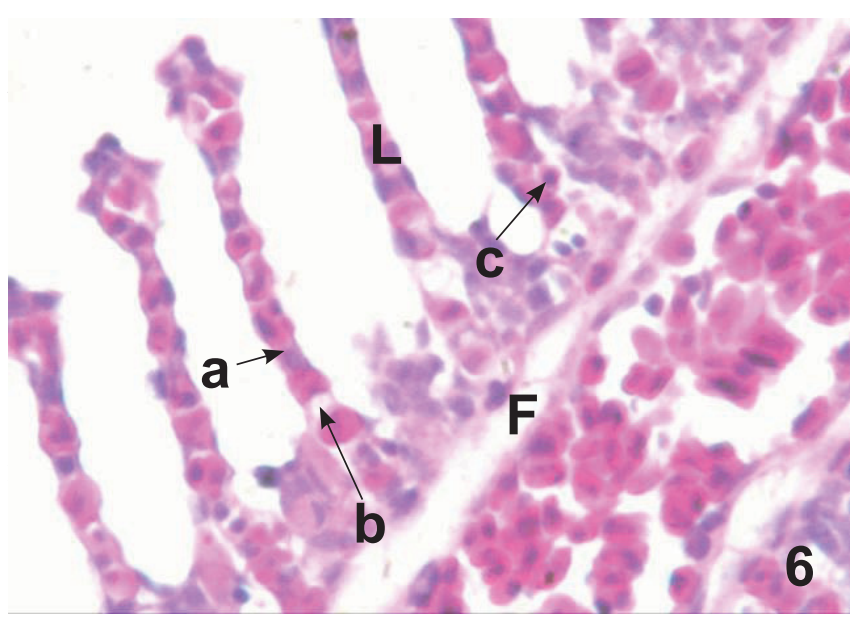

FIGURA 6: Filamento branquial de $S$. brevipinna. Células pilares (a); mucosas (b) e clorídrica (c), lamelas (L), filamentos (F) HE 400X. 
São observadas células mucosas encobertas pelas pavimentosas, tanto nos filamentos quanto nas lamelas, sendo responsáveis pela proteção das brânquias contra agentes externos, Fernandes e Perna-Martins (2001) estudando a espécie Prochilodus scrofa ressaltam a ausência destas células apenas nas lamelas, enquanto que Eiras-Stofella e Charvet-Almeida (1998) confirmam sua presença e com mais freqüência na sua porção distal lamelar.

Através da técnica de P.A.S. é possível confirmar reação positiva de glicoproteínas (Gps) neutras ou levemente ácidas das células mucosas (Figura 7), dados semelhantes foram observados nas brânquias de Micropogonias furnieri, Odontesthes bonariensis e Cynoscion guatucupa por Díaz et al. (2001; 2005a e b), indicando um controle na acidez do conteúdo da secreção mucosa.

A presença de GPs com dióis vizinhos oxidáveis nas células mucosas teve uma reação fortemente positiva nos rastros (Figura 8), apresentando uma camada espessa logo abaixo das células epiteliais pavimentosas superficiais. Mittal et al. (1994) comentam a forma de como as GPs com grupos dióis vizinhos oxidáveis regulam a acidez da secreção mucosa nas células mucosas da epiderme de Mastacembelus pancalus.

Estudos recentes destacam de forma significativa as células clorídricas em peixes de água doce, com a entrada de sódio e cloro em ambientes hiposmóticos, entrada de cálcio em ambientes com baixo teor deste íon e saída de prótons em ambientes ácidos, funções destas células (Perry et al., 1992; Patrick et al., 1997; Kaneko et al., 1999). Estas células podem ser facilmente reconhecidas pela intensa acidofilia, encontram-se nos filamentos, principalmente nas regiões entre as lamelas. Pisam et al. (1995 e 2000) determinaram pela microscopia eletrônica a presença de dois a três tipos de células clorídricas em peixes de água doce.

Em relação às células mucosas, sua importância é confirmada por Sabóia-Moraes et al. (1996), ao descreverem que os epitélios branquiais que apresentam estas células, desenvolveram um mecanismo de proteção, através de uma camada de GPs, constatado no aumento do número de células mucosas no epitélio branquial.

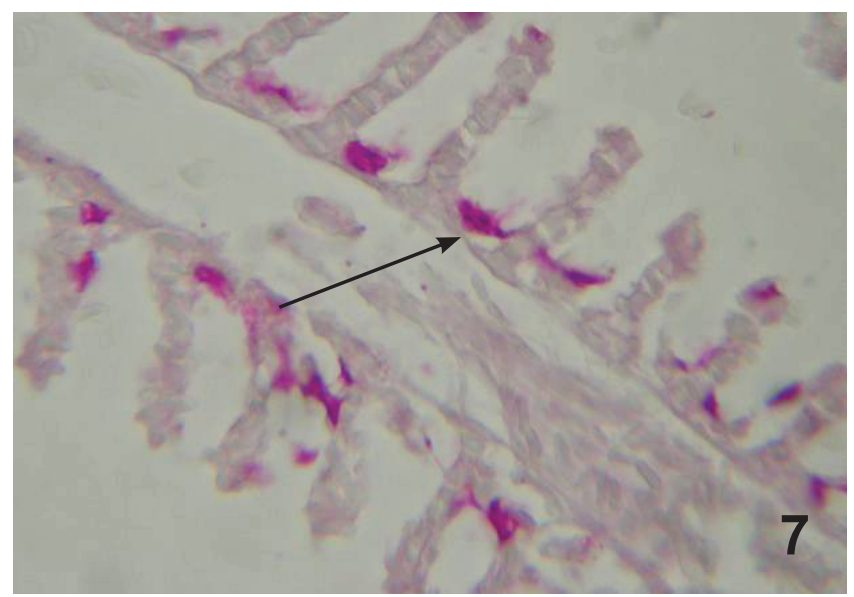

FIGURA 7: Filamento branquial de $S$. brevipinna. Células mucosas (seta). Reação positiva. P.A.S.400X.

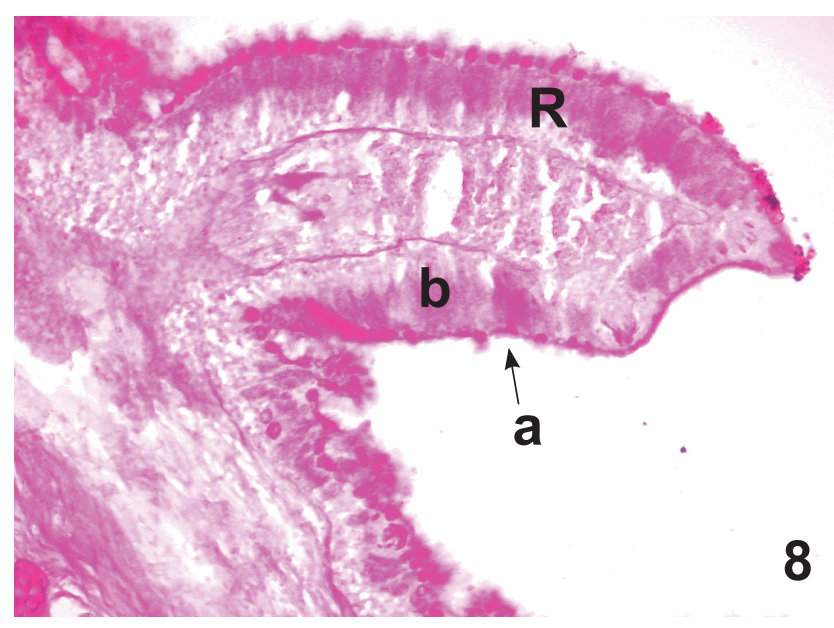

FIGURA 8: Rastro (R) das brânquias de S. brevipinna, epitélio (a); camada espessa de células mucosas (b), reação positiva. P.A.S. $400 \mathrm{X}$.

Steindachnerina brevipinna apresenta as características branquiais, semelhantes a outras espécies dulciaqüícolas, seguindo o padrão morfológico deste órgão, sendo adaptadas à proteção de agentes externos que venham ocorrer no meio, pela presença de células mucosas, células clorídricas que participam de forma intensa na osmorregulação, além de serem indicativas do estreito relacionamento com o hábito alimentar por apresentar corpúsculos gustativos que auxiliam na quimiorrecepção dos alimentos. A ocorrência e incidência destas estruturas branquiais permitem estabelecer relações com sua intensa atividade ecológica 
no ecossistema, como uma espécie ágil durante grande parte do dia e da noite, comparada com outras espécies, o que justifica seu importante papel no nível trófico.

\section{Agradecimentos}

À PUCRS -Campus Uruguaiana, pela acessibilidade nos diversos setores. À Fundação de Amparo a Pesquisa do Estado do Rio Grande do Sul (FAPERGS) por favorecer a realização deste trabalho através da bolsa de Iniciação Científica, ao Departamento de Biologia, da Faculdade de Ciências Exactas y Naturais, UNMDP - Mar del Plata, Argentina.

\section{Referências}

Barbieri, G.; Hartz, S. M. 1995. Estudo da fecundidade e tamanho de primeira maturação gonadal de Cyphocharax modesta (Hensel, 1869) na represa do lobo, estado de São Paulo, Brasil (Characiformes, Curimatidae). Iheringia, Série Zoologia, 8: 27-35.

Díaz, A. O.; Garcia, A. M.; Devincenti, C. V.; Goldemberg, A. L. 2001. Mucous cells in Micropogonias furnieri gills: Histochemistry and ultrastucture. Anatomia Histologia Embriologia, 30: 135-139. Díaz, A. O.; Garcia, A. M.; Devincenti, C. V.; Goldemberg, A. L. 2005a. Ultrastructure and histochemical study of glycoconjugates in the gills of the white croaker (Micropogonias furnieri). Anatomia Histologia Embriologia, 34: 117-122.

Díaz A. O.; García A. M.; Goldemberg A. L. 2005b. Glycoconjugates in the branchial mucous cells of Cynoscion guatucupa $(\mathrm{Cu}-$ vier, 1830). Scientia Marina, 69 (4): 545-553.

Eiras-Stofella, D. R. 2000. Gills of the seawater fish Oligoplites palometa (Carangidae): morphology and functional activity of structures described through scanning electron microscopy. Acta Biológica Paranaense, 29 (1, 2, 3, 4): 245-254.

Eiras-Stofella, D. R.; Charvet-Almeida, P. 1998. Ultrastructure (SEM) of the gills of prochilodus scrofa steindachner, 1881 (Pisces, Teleostei). Revista Brasileira de Zoologia, 15: 279-287.

Eiras-Stofella, D. R.; Charvet-Almeida, P.; Fanta, E.; Casagrande Vianna, A. C. 2001. Surface ultrastructure of the gills of the mullets Mugil curema, M. liza and M. platanus (Mugilidae, Pisces). Journal of Morphology, 247: 122-133.

Fernandes, M. N.; Perna-Martins, S. A. 2001. Epithelial gill cells in the armored catfish, Hypostomus cf. plecostomus (Loricariidae). Revista Brasileira de Biologia, 6 (1): 69-78.

Giora, J.; Fialho, C. B. 2003. Biologia alimentar de Steindachnerina brevipinna (Characiformes, Curimatidae) do rio Ibicuí-mirim, Rio Grande do Sul, Brasil. Iheringia, Série Zoologia, 93 (3): 277-281. Gremsky, W. 1975. Contribuição ao estudo ultra-estrutural do epitélio do trato digestivo de Pimelodus maculatus (Lacépède, 1803) (Pisces). Tese de Doutorado, Universidade de São Paulo, Brasil, 166pp.

Hossler, F. E. 1980. Gill arch of the mullet, Mugil cephalus. III. Rate of response to salinity change. American Journal of Physiology, 7: R160-R164.
Hossler, F. E.; Merchant, L. H. 1983. Morphology of taste buds on the gill arches of the mullet Mugil cephalus, and the killifish Fundulus heteroclitus. American Journal of Anatomy, 166: 299-312.

Hughes, G. M.; Byczkowska-Smyk, W. 1974. Ultrastructure of secondary gill lamella of the icefish, Chaenocephalus aceratus. Journal of Zoology, 174: 79-87.

Kaneko, T.; Hasegawa, S.; Uchida, K.; Ogasawara, T.; Oyagi, A.; Hirano, T. 1999. Acid tolerance of Japanese dace (a cyprinid teleost) in Lake Osorezan, a remarkable acid lake. Zoological Science, 16: $871-877$.

King, J. A. C.; Hossler, F. E. 1991. The gill arch of the striped bass (Morone saxatilis). IV. Alterations in the ultrastructure of chloride cell apical crypts and chloride efflux following exposure to seawater. Journal of Morphology, 209: 165-176.

Laurent, P. 1984. Gill internal morphology. In: Hoar, W. S. \& Randall, D. J. (Eds). Fish Physiology. v.10A. Academic Press, New York, USA, p.73-183.

Laurent, P.; Dunel S. 1980. Morphology of gill epithelia in fish. American Journal of Physiology, 238: R147-R159.

Machado, M. R.; Fanta, E. 2003. Effects of the organophosphorous methyl parathion on the branchial epithelium of a freshwater fish Metynnis roosevelti. Brazilian Archives of Biology and Technology, 46 (3): 361-372.

Mazon, A. F.; Fernandes, M. N.; Nolasco, M. A.; Severi, W. 1998. Functional morphology of gills and respiratory area of two active rheothilic fish species, Plagioscion squamosissimus and Prochilodus scrofa. Journal of Fish Biology, 52: 50-61.

McManus, J. F. A. 1948. Histological and histochemical uses of periodic acid. Stain Technology, 23: 99-148.

Mittal, A. K.; Ueda, T.; Fujimori, O.; Yamada, K. 1994. Histochemical analysis of glycoproteins in the unicellular glands in the epidermis of na Indian freshwater fish, Mastacembelus pancalus (Hamilton). Histochemic Journal, 26: 666-677.

Patrick, M. L.; Wood, C. D.; Marshall, W. S. 1997. Calcium regulation in the freshwater-adapted mummichog. Journal of Fish Biology, 51: 135-145.

Perry, S. F.; Goss, G. G.; Laurent, P. 1992. The interrelationships between gill chloride cell morphology and ionic uptake in four freshwater teleosts. Canadian Journal of Zoology, 70: 1775-1786.

Pisam, M.; Le Moal, C.; Auperin, B.; Prunet, P.; Rambourg, A. 1995. Apical structures of "mitochondria-rich" $\alpha$ and $\beta$ cells in euryhaline fish gill: their behaviour in various living conditions. The Anatomical Record, 241: 13-24.

Pisam, M.; Massa, F.; Jammet, C.; Prunet, P. 2000. Chronology of the appearance of beta and alfa mitochondria-rich cells in the gill epithelium during ontogenesis of the brown trout (Salmo trutta). The Anatomical Record, 259: 301-311.

Sabóia-Moraes, S. M. T. 1991. Histologia de brânquias. In: Santos, H. S. L. (Ed.). Histologia de Peixes. Editora Funep, Jaboticabal, Brasil, p.26-28.

Sabóia-Moraes, S. M. T.; Hernandes-Blazquez, F. J.; Mota, D. L.; Bittencourt, A. M. 1996. Mucous cell types in the branchial epithelium of the euryhaline fish Poecilia vivipara. Journal Fish Biology, 49: 545-548.

Tolosa, E. M.; Behmer, O. A.; Neto, A. G.; Rodrigues, C. J. 2003. Manual de Técnicas para Histologia Normal e Patológica. $2^{\mathrm{a}}$ ed. Manole, Barueri, Brasil, 331pp. 